\title{
Algunos problemas de origen externo que enfrentan las comunidades en zonas ex-conflictivas. ${ }^{1}$
}

\author{
Aquiles Montoya
}

\section{La Propiedad de la Tierra y de la Vlvienda.}

La problemática que se les presenta a las comunidades en cuanto a la propiedad de la tierra, es bastante compleja, en primer lugar se tiene que hasta el momento no ha habido transferencias de propiedad, lo cual genera inseguridad entre sus moradores y a su vez se constituye en un obstáculo para realizar obras de inversión. Pero suponiendo que las transferencias se agilizaran, el problema sólo estaría resuelto parcialmente con las propiedades transferidas. Ya que en segundo lugar tenemos que muchos propietarios no desean vender y se están organizando a fin de recuperar sus propiedades, esto se presenta con mayor fuerza cuando observan que sus propiedades se han apreciado en razón de las construcciones que se han efectuado en las mismas. En otras ocasiones, sencillamente, es el deseo de no vender, ya sea por razones. de precio, afectivas, $\theta$ incluso, políticas. En tercer lugar, tenemos que algunos propietarios que desean vender no pueden hacerlo debido a que no cuentan con los títulos de propiedad que les exige el Banco de Tierras, para las transacciones. En cuarto lugar, encontramos que no toda la

1. El presente trabajo es parte de nuestra próxima publicación, La Nueva Economia Popular: una aproximación empírica. Con el cual pretendemos derle continuidad a nuestras investigaciones anteriores sobre esta temática. 
tierra ocupada por las Comunidades lue inventariada, lo cual dificulta aún más la posibilidad de ser adquirida. Finalmente tenemos que ante la decisión del propietario de no vender, las Comunidades no cuentan con mayores alternativas legales para acceder a la tierra, a no ser medidas de hecho, las cuales pudieran derivar en serios conflictos sociales. Sobre todo si tenemos en cuenta que se trata de comunidades muy bien organizadas y con disposición muy grande a defender la tierra que actualmente ocupan.

Siendo la tierra un elemento vital para el desarrollo de la Nueva Economla Popular, ya sea como lugar donde construir o lugar donde trabajar, la no delinición de la tenencia de la misma, se está constituyendo en grave obstáculo para el desarrollo de las comunidades, ya que como se nos explicaba por dirigentes del CCR en Chalatenango, la inseguridad limita posibles acciones a desarrollar por las comunidades, o continuar realizando obras de infraestructura, como las que construyeron durante los años de la guerra. Adicionalmente, se les dificulta el acceso al crédito por las mismas razones, ya que la banca privada les exige garantias de propiedad.

Aunque en las Comunidades por nosotros esludiadas no se habla realizado ninguna transferencia, los miembros de CEA-COPAZ, manifestaron el 27 de Sepliembre de este año que el proceso está cumplido en un $8 \%$ y que se buscaba agilizar las transferencias mediante un "plan de emergencia". (Diario Latino, 27,9,93).

En lo que respecta a las casas de habitación o de uso público, la problemática es más deslavorable a las Comunidades que ocuparon y reacondicionaron aquellas viviendas abandonadas por sus propietarios, - locales de alcaldias, escuelas, etc. a las cuales se les ha dado otro uso, pero que en los Acuerdos de Paz, tal parece que no existe ninguna disposición, al respecto. Asi hemos observado, locales de alcaldias transformadas en guarderlas, o bien, locales de escuelas que ahora son bodegas para explotaciones ganaderas, debido a que en la zona no quedaron habitantes, etc. El problema de la posesión de viviendas e Infraestructura pública, ha sido al punto descuidado que a casi dos años de firmados los Acuerdos de Paz, hasta ahora se está proyectando efectuar un Censo Urbano de Viviendas Ocupadas por parte de CEACOPAZ, para luego buscarle una solución adecuada al problema. (D.L. 27,9,93)

¿Qué alternativas cabrla plantear sobre esta problemática? Procederemos a efectuar una serie de consideraciones y luego planteáramos algunas altemativas de solución. 
En muchas comunidades de repobladores y repatriados se presenta en la actualidad un nuevo problema: cual es el de las casas, locales y edilicios, los cuales fueron reconstruidos, reparados o sencillamente ocupados para otros fines y por otras personas. Durante varios años nadie cuestionó tales ocupaciones, eran los años de la guerra, durante los cuales vivir en las zonas conflictivas implicaba un alto riesgo, tan alto que podría costar la vida. Pero aún asl hubo quienes cansados de guindear, se fueron a los refugios y harlos del encierro en los refugios decidieron reiniciar sus vidas en aquellas regiones abandonadas, en aquellos pueblos fantasmas y con mucho trabajo colectivo y ayuda internacional, revitalizaron a aquellos pueblos literalmente muertos.

En condiciones normales la ley reconoce la propiedad a aquel poseedor que ha efectuado las labores propias de un propietario: construir, reparar, habitar, cultivar, etc. durante diez años consecutivos. Cabria preguntarse ¿cuál es la razón que los legisladores tuvieron para aceptar que en tales circunstancias se expropie al propietario legal, sin ninguna indemnización? Tal respuesta corresponde, obviamente, a los prolesionales del derecho; sin embargo cabe suponer que fue una razón de justicia, la cual le da sentido a cualquier legislación.

En el caso que nos ocupa se trata de condiciones excepcionales, se trata de personas organizadas que, aún a riesgo de perder su vida, decidieron ocupar y efectuar las labores propias de los propietarios. Fue asl como reconstruyeron, repararon, $e$ inclusive, construyeron nuevas edificaciones para servicio familiar y comunal. Ciertamente, en tierras de las cuales no eran los propietarios legales. Pero en tanto que Comunidades preocupadas por satisfacer sus necesidades económicas y sociales, montaron talleres, cultivaron la tierra, desarrollaron actividades pecuarias: ganaderas, avicolas, porcícolas, cunicolas y apicolas. Establecieron centros de educación de niños y adultos, alfabetizaron y capacitaron a su población y montaron unidades de salud. Realizaron, pues, actividades de interés social para sus comunidades.

En los Acuerdos de Paz se estableció el derecho de los tenedores sobre la tierra, al punto de establecer que no se les podría expulsar inmediatamente, sino que se buscarla que los propietarios legales vendieran, si asl lo deseaban y en caso contrario, se buscarla reubicar a los tenedores. La solución hubiese sido más apegada a la justicia, si tal alternaliva se hubiera planteado también para los propietarios. Lo cual no niega la posibilidad de hacerlo, en tanto que el Estado cuenta en su haber con tierras disponibles, que perfectamente podrla ofrecer a los propietarios legales de tierras ocupadas. Alternativa que no debe de descartarse, si lo que buscamos son soluciones para vivir en paz y con 
justicia.

Ahora bien, si se estableció lo anterior sobre lo más, cabe suponer que es aplicable a lo menos, cual sería el espacio físico o de tierra que ocupan algunas edificaciones con sus respectivos solares, cual es la costumbre en los pueblos. En consecuencia, para la posesión de edificaciones existen diferentes alternativas: la primera serla, que se tratara el caso como en el de las tierras, conforme a los Acuerdos de Paz, esto es la venta voluntaria del espacio lísico o sea de la tierra en la cual se encuentran las edificaciones construidas o reconstruidas.

Una segunda alternativa, sería la que establece el Código Civil, libro segundo, título cuarto, art. 650 . Esto es que se proceda a indemnizar a los poseedores; sin embargo esto tendrla mayores costos económicos, sociales y políticos. Lo que si no pueden hacer los propietarios legales es llegar y sencillamente, lanzar a los poseedores y apropiarse de las edificaciones y obras de carácter comunal o público.

Una tercera alternativa sería la que presenta el art. 106 de la Cp: "La expropiación procederá por causa de utilidad pública o de interés social, legalmente comprobados, y previa una justa indemnización.

Cuando la expropiación sea motivada por causas provenientes de guerra....la indemnización podrá no ser previa."

Es claro, que los propietarios legales de las comunidades de repobladores o repatriados, abandonaron sus propiedades en razón de la guerra; pero también es cierto que ellos ya están reubicados, después de doce años de guerra ya han encontrado un nuevo modus vivendi, diferente al del pasado. En cambio, los repobladores que han reconstruido o construido nuevos asentamientos humanos con su esfuerzo, con su trabajo, algunos desde 1986, no tienen otra alternativa de vida. Pero es que adicionalmente, ellos han habilitado calles, provisto de agua potable, en algunos casos hasta instalaciones de energía eléctrica con sus propias plantas, letrinas, locales para medicina general y odontológica, para guarderlas, kinders y escuelas, casas comunales, reforestaciones, etc. En consecuencia, resulta bastante claro que la expropiación procede por causa de interés social y que adicionalmente, debe de realizarse sin previa indemnización, en razón de que ésta se origina en causas provenientes de guerra, como lo señala la Constitución Política, en el artículo antes citado.

En justicia, las comunidades de repobladores y repatriados, no pueden ser expulsados de los lugares donde actualmente habitan, hacerlo equivaldría a encender la mecha para una nueva explosión social, de allf 
que el actual gobierno, o cualquiera otro futuro, es preciso que actúe con responsabilidad, con justicia y con sentido social. La Paz, se ha dicho, tiene sus costos y todos debemos aportar, de una u otra forma, lo que nos corresponde.

\section{La Legalidad.}

Esta cubre un amplio espectro desde la vinculada al literal anterior hasta la legalidad de las personas, de la educación, de la salud, etc. Aún en la actualidad, pese a los muchos esfuerzos realizados, existen personas en las Comunidades de repatriados o repobladores que no cuentan con sus documentos de identidad personal, razón por la cual viven como ilegales en su propio pals.

Pero la ilegalidad también se presenta con los educadores populares y con la educación misma. En este caso se presentan diferencias en algunas comunidades, ya que en algunas escuelas populares se ha reconocido la educación, permitiendo el que se otorguen certificados del Ministerio de Educación, aunque no se efectúa por parte del Gobierno los pagos a los educadores. En otras, no se reconoce ni los estudios, ni a los profesores, pese a que en más de alguna Comunidad, realicen una labor educativa superior a muchas de las escuelas privadas del área urbana del país. Cual sería, por ejemplo, la educación a partir del lenguaje integral que se ha venido impartiendo en la Ciudadela Ungo.

Semejante es el caso de la salud, aunque acá el mayor problema provenga no tanto de que no se reconozca oficialmente a los sistemas de salud existentes, sino de que el Gobiemo no asuma los costos de la misma, en lo referente a personal, a medicamentos, equipo, etc. Actualmente se prestan servicios a la población de las comunidades, gracias a las donaciones, pero la tendencia de éstas es a que disminuyan, hasta desaparecer por completo. Cuando esto ocurra, no sólo habrá un desmejoramiento en la salud, sino que se generará desempleo entre quienes han venido realizando este trabajo, de all que sea urgente el que el Gobierno asuma las responsabilidades que le competen en estos campos.

\section{La falta de apoyo económico del gobierno, para las áreas socia- les y las necesidades de infraestructura.}

Este apartado está muy vinculado al anlerior, al menos, en lo que se refiere a educación y salud. Respecto a estas áreas el Gobierno no ha querido aceptar que en las comunidades de repobladores y repatriados 
se ha ido generando una realidad muy diferente a la tradicional y que en razón de ella, no puede darle el mismo tratamiento que a cualquiera otra comunidad. Es asl como los integrantes de eslas comunidades exigen que se les respete y reconozca lo logrado. Asl, por ejemplo, no se ha aceptado que por ser el gobiemo quien va a pagar a los prolesores sea éste quien decida qué profesores van a trabajar, cuando la Comunidad ya posee su propio sistema de educación con sus propios educadores. Semejante es el caso en salud, con los promotores populares y el personal auxiliar. Seguramente no poseen un título pero conocen su trabajo y gozan de la confianza de los usuarios, lo cual es de suma importancia. Se habla mucho de la autonomla local, pero cuando las comunidades organizadas pretenden decidir sobre aspectos que les atañen solamente a ellos, el Gobierno lo que hace es negarles el apoyo económico.

Por otra parte en lo que a infraestructura se refiere, algunas comunidades han logrado crear la mínima necesaria para prestar los servicios que requiere la Comunidad, gracias a donaciones, pero los fondos del Plan de Reconstrucción Nacional, no aparecen por ningún lado, a no ser para realizar labores cosméticas cuales son, por ejemplo, el adoquinado de algunas calles de la localidad municipal. $Y$ esto ha ocurrido, incluso, cuando en los cabildos abiertos la Comunidad ha señalado otras prioridades.

Podriamos señalar a manera de ejemplos concretos las comunidades del nor-oriente de Chalatenango que no poseen ni caminos transitables, ni energla eléctrica, ni servicios de telecomunicaciones o de agua potable. Lo poco que se puede observar ha sido gracias a los esfuerzos de las comunidades. O bien, todo el norte de Morazán, más allá del río Torola que sigue en espera de que se restaure los servicios de energía eléctrica.

Es claro que la no resolución de los anteriores problemas se convierte en serio obstáculo, no sólo para el desarrollo social de las comunidades, sino para el mismo desarrollo económico, ya que la ausencia de calles transitables y/o de energla eléctrica elevan significativamente los costos de transporte o los de producción, sobre todo en aquellas zonas que en razón de la pobreza de sus suelos, se busca propiciar y desarrollar actividades económicas no agrícolas y el contar con energla eléctrica se torna un factor clave.

\section{Un llamado de urgencia.}

Los esfuerzos en los ámbitos económico y social, emprendidos por las comunidades, se presentan como una manera eficaz y eficiente de 
combatir la pobreza y la marginación social, de allí que el gobiemo y la comunidad internacional, deberían de ponerles más atención y actuar conforme a las necesidades de estas poblaciones. Asl el gobierno deberla de cumplir sus obligaciones constitucionales asumiendo las tareas que le competen y la comunidad internacional, vigilar para que sus donaciones se canalicen a las zonas que realmente fueron afectadas por el conflicto y adicionalmente, no retirar su colaboración en estos momentos que se presentan cruciales para la consolidación de estos esfuerzos emprendidos por las comunidades de repobladores y repatriados. Existe toda una experiencia ganada que debe de conservarse y fortalecerse, cuando menos en las áreas de educación y salud, que son las que corren un mayor riesgo de ser suspendidas al no ser asumidas por el gobierno, ya que han venido operando gracias a las donaciones del exterior. 